\title{
Improvements in Behaviour and Self-Esteem following Growth Hormone Treatment in Short Prepubertal Children
}

\author{
John Eric Chaplin ${ }^{a}$ Berit Kriström ${ }^{a, b}$ Björn Jonsson ${ }^{c}$ Bruno Hägglöf ${ }^{b}$ \\ Torsten Tuvemo ${ }^{c}$ A. Stefan Aronson ${ }^{d}$ Jovanna Dahlgren ${ }^{a}$ \\ Kerstin Albertsson-Wikland ${ }^{a}$ \\ ${ }^{a}$ Göteborg Pediatric Growth Research Center, Institute of Clinical Science, The Sahlgrenska Academy at University \\ of Gothenburg, Göteborg, ' Department of Clinical Science, Umeå University, Umeå, 'Department of Women's \\ and Children's Health, Uppsala University, Uppsala, and d Department of Pediatrics, The Central County Hospital of \\ Halmstad, Halmstad, Sweden
}

\section{Key Words}

Self-perception - Quality of life - Short-stature children, psychosocial variables $\cdot$ Idiopathic short stature $\cdot$ Growth hormone deficiency

\footnotetext{
Abstract

Background/Aims: To evaluate effects of growth hormone (GH) treatment on behaviour and psychosocial characteristics in short-stature children. Methods: 99 referred prepubertal non-familiar short-stature children $(32 \mathrm{GH}$ deficiency; 67 idiopathic short stature) aged 3-11 years, randomized to fixed or individual GH doses and their parents completed questionnaires (Child Behaviour Checklist, Birleson Depression Self-Report Scale, Abbreviated Parent-Teacher Questionnaire, I Think I Am, Well-Being Visual-Analogue Scales for Short-Stature Children) at baseline (BL) and after 3, 12, and 24 months. Results: At BL, children showed higher levels of internalizing behaviour $(p<0.001)$, lower levels of externalizing behaviour $(p<0.006)$ and self-esteem $(p<0.001)$ compared to reference values. During GH treatment, behavioural measures $(p<0.001)$ and depression $(p<0.01)$ changed to-
}

wards the mean of the population within the first 3 months and remained improved to 24 months. Self-esteem improved at all time points $(p<0.001)$, and in all subgroups, as did well-being dimensions stability and mood $(p<0.05)$. Multiple regression analysis showed that greater improvements were related to lower $\mathrm{BL}$ value, height gain, higher maximal $\mathrm{GH}$ value, being older, and being male. Conclusion: $\mathrm{On} \mathrm{GH}$ treatment, prepubertal short children significantly improved on behavioural, depression, and psychosocial evaluations over a 2-year period of $\mathrm{GH}$ treatment. Most change occurred within the first 3 months, which highlights this short period as important not only for growth and metabolic changes but also for behaviour and psychosocial improvements following $\mathrm{GH}$ treatment.

Copyright $\odot 2011$ S. Karger AG, Basel

\section{Introduction}

The effects of growth hormone (GH) treatment can be profound for a child with short stature. Not only does the child grow taller towards a normalized height, but 
he/she may be released from social or psychological burdens attributable to short stature [1]. Release from these burdens is likely to be reflected in changes in the child's attitudes towards its height, as well as its expressive and internalized behaviours, and not least, in its feelings of well-being and self-esteem. Height gain, although often the primary outcome of GH treatment can also be taken as an indicator of social and psychological changes in the individual. Evidence shows that there are no significant differences in height gain following GH treatment between children with GH deficiency (GHD) and children with idiopathic short stature (ISS) when GH dosing is based on estimated individual responsiveness to $\mathrm{GH}$ [2]. In addition to a well-known dose-dependent effect on growth in GHD, also found in ISS children [3], there are other GH-related benefits in short children. Relative to before treatment, short children receiving GH have been described to have improved energy levels, cognition [4], and quality of life (QoL) improvements, defined as improvements in self-esteem and well-being [5]. These populations include short children born small for gestational age (SGA) [4], ISS [6], and ISS/GH-deficient children [7]. At baseline (BL), short children have been shown to have lower self-esteem [8], poor concentration [9], and lower scholastic ability [10] compared to a reference population. Dissatisfaction with height has been described in short children [11,12] and this can lead to poor psychological adaptation [4, 13]. These problems, however, did not occur at all ages and some evidence suggests that it is only during adolescence [14] or perhaps during adulthood $[15,16]$ that problems emerge. The reasons for such problems are multifaceted but seem to be related to social acceptance and/or perception of short stature within the community [17-20].

The aim of this study was to assess changes during $\mathrm{GH}$ treatment in two areas of QoL: (1) behaviour, including feelings of depression and problems with attention, and (2) psychosocial estimates of self-esteem and well-being. The study was carried out alongside a prospective, randomized, clinical trial of GH therapy during the initial 2 years of the catch-up growth phase, which was studying effects of individualized versus fixed GH dose regimens in short prepubertal children, short both in relation to population and to parents. The study included both children with GHD and ISS; although responsiveness to GH treatment regarding growth is different in these two subpopulations [2], little is known about changes in behaviour and QoL.

\section{Subjects and Methods}

\section{Ethics}

The psychosocial protocol was approved by the Ethics Committees of the Universities of Gothenburg (for Göteborg and Halmstad), Umeå and Uppsala and the Medical Product Agency of Sweden. Written informed consent was obtained from all parents, and children if old enough.

\section{Study Design}

This study was carried out as an auxiliary independent study in four of the five centres conducting a randomized multi-centre clinical trial of an individualized (67\%) or a fixed standard dose (33\%) of GH in short children, of whom $75 \%$ were GH-deficient and $25 \%$ were ISS based on the results of maximal GH value $\left(\mathrm{GH}_{\max }\right)$ on the arginine-insulin tolerance test (AITT). The study design (No. TRN 98-0198-003) has been described elsewhere [2]. Differences between the randomized groups were investigated. At a later time point, the children born appropriate for gestational age were reclassified as having GHD or ISS using spontaneous $\mathrm{GH}_{\max }$ from a 24-hour profile (67 ISS and $32 \mathrm{GHD}$ ). There were similar proportions of patients with ISS and GHD (ISS 68\%) within the two dose regimen groups. Subjects and parents were given a psychosocial evaluation by a chartered psychologist at study start, and after 3,12, and 24 months of GH treatment.

\section{Study Population (table 1)}

Study participants referred to a growth clinic because of short stature were prepubertal, aged 3-11 years at BL, with proportionate short ( $<-2$ standard deviation score (SDS)) stature and at least 1 SD below midparental height (MPH) SDS. Therefore, the bone age was retarded ( $-1.4 \pm 0.94$ years), since children with familiar short stature (FSS) were not included, here defined as both mother and father height SDS $<-2$ SDS of the population. See a previous report for details of the 128 children in the per-protocol population of the main study [2]. This QoL study investigated 114 children from the per-protocol population of the original study who came from 4 sites. Of the 114 children, 99 completed the psychosocial evaluations and 15 were excluded from analyses (3 were born SGA, 5 lacked BL psychological data, and 7 had missing follow-up psychological data).

Mean age at study entry was $7.3 \pm 2.08$ years and height ${ }_{\mathrm{SDS}}$ was $-2.7 \pm 0.43$. There was no difference in age or height $\mathrm{SDS}$ between genders. Height ${ }_{\mathrm{SDS}}$ had increased by $1.33 \pm 0.48$ after 2 years of GH treatment; results were comparable for the GH-deficient $(1.35 \pm 0.46)$ and ISS $(1.32 \pm 0.49)$ groups.

Maternal and paternal education levels were divided into three categories. Compared to education levels in the general population aged 25-65 in 2001-2003 [www.scb.se], there was an over-representation of mothers in the basic education level, 27 versus $18 \%$ in the general female population $(\mathrm{p}<0.015)$, whereas for fathers there were fewer in the middle education category, 39 versus $50 \%$ in the general male population $(\mathrm{p}<0.045)$. The study sample is representative of the social distribution of the short-stature population [21].

\section{Height Evaluations}

The childhood component of the Swedish population-based growth reference values was used for the height-related inclusion criteria for the children and to assess changes in height longitudinally [22]. For parental heights the total reference values at 18 
Table 1. BL characteristics and growth outcome at 24 months of the total, ISS and GHD groups, all divided by gender

\begin{tabular}{|c|c|c|c|c|c|c|c|}
\hline & $\mathrm{n}=99$ & males, $\mathrm{n}=70$ & females, $n=29$ & males, $\mathrm{n}=48$ & females, $\mathrm{n}=19$ & males, $\mathrm{n}=22$ & females, $\mathrm{n}=10$ \\
\hline Age, years & $7.30 \pm 2.076$ & $7.40 \pm 2.261$ & $7.05 \pm 1.548$ & $7.48 \pm 2.388$ & $7.29 \pm 1.389$ & $7.20 \pm 1.971$ & $6.59 \pm 1.795$ \\
\hline Height $_{\text {SDS }}$ & $2.66 \pm 0.426$ & $-2.64 \pm 0.424$ & $-2.71 \pm 0.435$ & $-2.68 \pm 0.456$ & $-2.63 \pm 0.435$ & $-2.56 \pm 0.339$ & $-2.86 \pm 0.413$ \\
\hline $\mathrm{MPH}_{\mathrm{SDS}}$ & $0.94 \pm 0.638$ & $-0.87 \pm 0.688$ & $-1.08 \pm 0.476$ & $-0.88 \pm 0.916$ & $-1.09 \pm 0.697$ & $-0.80 \pm 0.677$ & $-1.16 \pm 0.304$ \\
\hline $\mathrm{BMI}_{\mathrm{SDS}}$ & $0.42 \pm 1.059$ & $-0.46 \pm 1.051$ & $-0.32 \pm 1.09$ & $-0.54 \pm 1.077$ & $-0.72 \pm 0.98$ & $-0.30 \pm 0.997$ & $0.45 \pm 0.893$ \\
\hline Bone age delay & $-1.39 \pm 0.942$ & $-1.42 \pm 1.000$ & $-1.32 \pm 0.795$ & $-1.31 \pm 1.053$ & $-1.19 \pm 0.820$ & $-1.66 \pm 0.845$ & $-1.56 \pm 0.720$ \\
\hline IGF-I SDS & $-1.05 \pm 1.079$ & $-1.29 \pm 0.967$ & $-0.48 \pm 1.141$ & $-1.27 \pm 1.000$ & $-0.51 \pm 1.227$ & $-1.31 \pm 0.914$ & $-0.44 \pm 1.02$ \\
\hline \multicolumn{8}{|l|}{ At 24 months } \\
\hline$\Delta$ Height $_{\mathrm{SDS}}, 24 \mathrm{M}-\mathrm{BL}$ & $1.33 \pm 0.481$ & $1.29 \pm 0.462$ & $1.43 \pm 0.517$ & $1.30 \pm 0.480$ & $1.38 \pm 0.527$ & $1.27 \pm 0.432$ & $1.52 \pm 0.509$ \\
\hline
\end{tabular}

Values are given as mean $\pm \mathrm{SD}$ at $\mathrm{GH}$ start and after 2 years on $\mathrm{GH}$.

years were used [22]. All heights were expressed in SDS. MPH in this study was defined as the mean of measured paternal and maternal height $\mathrm{SDS}$.

\section{Hormonal Analyses}

Analysis of GH secretion was performed at the GP-GRC laboratory (Swedac accredited No. 1899). Both AITT and 24-hour GH profiles were analysed. The cut-off value for the diagnosis of GHD was 'the old $10 \mu \mathrm{g} / \mathrm{l}$ ' corresponding to $32 \mathrm{mU} / \mathrm{l}$ using a polyclonal assay and WHO International Reference Preparation 80/505 [23].

\section{QoL Evaluations}

Behavioural Assessment

The Child Behaviour Checklist (CBCL) [24] was completed by the parents $[25,26]$. Swedish reference data were available from 685 children ( $48 \%$ girls) aged $4-12$ years (mean age $7.8 \pm 2.58$ ) [27]. In order to standardize the influence on results from age and gender, stepwise regression analyses on raw data were used with age and gender as explanatory variables in analyses. Predicted values and residual SD for each variable were obtained for the reference children and used for the calculation of SDS for children in this study. SDS was defined as (observed value - predicted value)/residual SD.

The Birleson Depression Self-Report Scale (BDSRS) [28, 29] was completed by the child. A child scoring between 13 and 16 was considered to have clinically relevant signs and symptoms of depression.

Connors' Abbreviated Parent-Teacher Questionnaire (APTQ) was used for measuring attention and over-activity. A score of 15 on the combined subscales represents $2 \mathrm{SD}$ above the mean for the scale (approximately $2 \%$ of a normal population) and can be used for quasi-diagnostic identification of clinically significant hyperactivity [30].

Psychosocial Assessment

Self-esteem was assessed using the 'I Think I Am' (ITIA) child self-report scale [31]. Normative data were available from 3,465 children between the ages of 7 and 16 years [31]. Higher scores in- dicate stronger self-esteem. The physical attributes scale assesses the child's satisfaction with facial appearance and physique. Body image was derived from a question about satisfaction with height.

The Well-Being Visual Analogue Scale for Short Stature Children (VASc) and the Parent Version (VASp) $[7,8,32]$ was designed as a measure for use in children with short stature. This scale has been shown to have good internal consistency and reliability. Dimensions that can be identified are: alertness, self-esteem, mood, elation, stability, vitality and overall well-being.

\section{Statistical Methods}

Conventional descriptive statistics were used; means and SDs are given. Tests of central tendency were performed using nonparametric tests. For paired samples, the Wilcoxon signed-ranks test was used, and for independent samples the Mann-Whitney U test. Analyses of equality of variances were performed using the Levene test. Spearman's $\rho$ was used for bivariate correlation analyses. $p$ values on two-tailed tests $<0.05$ were considered statistically significant.

In order to measure the impact of predictors on the QoL, multiple stepwise forward regression analyses were used. The variables included were: age, gender $(b=0, g=1)$, gain in height from $\mathrm{BL}, \mathrm{GH}$ dose, $\mathrm{GH}_{\max }$ (maximum of $24 \mathrm{~h}$ or AITT), and difference between current height ${ }_{S D S}$ of the child and $\mathrm{MPH}_{\mathrm{SDS}}\left(\mathrm{diffMPH}_{\mathrm{SDS}}\right)$ at BL. Analyses were carried out using the Statistical Package for Social Sciences (SPSS), version 15 (SPSS Inc., Chicago, Ill., USA).

\section{Results}

\section{Behaviour Variables}

Child Behaviour Checklist - CBCL (table 2; fig. 1, 2)

At $\mathrm{BL}$, the total study population had significantly higher scores for internalizing problems $(p<0.006)$ than 
Table 2. CBCL (SDS), BDSRS estimated by the parents of the total study group and the child self-esteem estimated by ITIA, and wellbeing by VASp by the parents at BL and 3, 12, and 24 months on GH treatment in the total study group

\begin{tabular}{|c|c|c|c|c|c|c|c|c|c|c|c|c|}
\hline & \multicolumn{3}{|c|}{ Baseline } & \multicolumn{3}{|c|}{3 months } & \multicolumn{3}{|c|}{12 months } & \multicolumn{3}{|c|}{24 months } \\
\hline \multicolumn{13}{|l|}{$C B C L$ parent } \\
\hline Internalizing (SDS) & 79 & $0.8 \pm 0.199$ & $<0.006$ & 63 & $-0.87 \pm 0.191$ & $<0.001$ & 62 & $-1.11 \pm 0.226$ & $<0.001$ & 64 & $-1.06 \pm 0.19$ & $<0.001$ \\
\hline Externalizing (SDS) & 68 & $-0.35 \pm 0.107$ & $<0.001$ & 60 & $0.33 \pm 0.168$ & $<0.06$ & 60 & $0.39 \pm 0.152$ & $<0.04$ & 59 & $0.27 \pm 0.133$ & $<0.04$ \\
\hline Thought problems (SDS) & 93 & $0.17 \pm 0.244$ & $<0.001$ & 82 & $-0.14 \pm 0.289$ & & 88 & $-0.36 \pm 0.255$ & $<0.001$ & 90 & $-0.39 \pm 0.252$ & $<0.001$ \\
\hline Anxious/depressed (SDS) & 78 & $0.00 \pm 0.110$ & & 71 & $-0.17 \pm 0.11$ & & 73 & $-0.09 \pm 0.115$ & $<0.022$ & 71 & $-0.14 \pm 0.096$ & $<0.023$ \\
\hline Withdrawn (SDS) & 85 & $0.10 \pm 0.094$ & & 74 & $-0.16 \pm 0.156$ & & 82 & $-0.24 \pm 0.103$ & $<0.071$ & 78 & $-0.37 \pm 0.111$ & $<0.001$ \\
\hline Aggressive (SDS) & 82 & $0.19 \pm 0.154$ & & 76 & $-0.19 \pm 0.108$ & & 74 & $-0.27 \pm 0.124$ & $<0.105$ & 77 & $-0.16 \pm 0.11$ & \\
\hline Rule-breaking (SDS) & 89 & $0.25 \pm 0.138$ & & 79 & $-0.24 \pm 0.129$ & $<0.036$ & 81 & $-0.37 \pm 0.136$ & $<0.025$ & 79 & $-0.3 \pm 0.191$ & $<0.008$ \\
\hline Somatic complaints (SDS) & 87 & $-0.03 \pm 0.101$ & & 79 & $-0.06 \pm 0.125$ & & 74 & $0.01 \pm 0.159$ & & 74 & $0.02 \pm 0.142$ & $<0.011$ \\
\hline BDSRS & 78 & $8.13 \pm 0.492$ & & 66 & $-1.41 \pm 0.454$ & $<0.003$ & 75 & $-1.31 \pm 0.504$ & $<0.01$ & 74 & $-2.09 \pm 0.712$ & $<0.003$ \\
\hline Total score & 94 & $4 \pm 0.47$ & & 89 & $0.1 \pm 0.41$ & & 86 & $-0.5 \pm 0.36$ & & 86 & $-0.4 \pm 0.63$ & \\
\hline \multicolumn{13}{|l|}{ ITIA child } \\
\hline Physical attributes (stanine) & 83 & $3.3 \pm 0.06$ & $<0.001$ & 77 & $0.0 \pm 0.07$ & & 79 & $0.1 \pm 0.07$ & & 80 & $0.1 \pm 0.07$ & \\
\hline Psychological strength (stanine) & 77 & $3.4 \pm 0.10$ & $<0.001$ & 68 & $0.1 \pm 0.08$ & & 73 & $0.2 \pm 0.10$ & $<0.099$ & 67 & $0.2 \pm 0.12$ & \\
\hline Talent-achievement (stanine) & 72 & $3.8 \pm 0.07$ & $<0.001$ & 66 & $0.1 \pm 0.08$ & & 68 & $0.1 \pm 0.08$ & & 70 & $0.3 \pm 0.10$ & $<0.007$ \\
\hline Family relationships (stanine) & 75 & $1.7 \pm 0.07$ & $<0.001$ & 68 & $0.1 \pm 0.07$ & $<0.061$ & 73 & $0.2 \pm 0.07$ & $<0.001$ & 53 & $0.5 \pm 0.10$ & $<0.001$ \\
\hline Social relationships (stanine) & 72 & $3.0 \pm 0.08$ & $<0.001$ & 64 & $0.1 \pm 0.06$ & & 66 & $0.2 \pm 0.08$ & $<0.016$ & 65 & $0.3 \pm 0.09$ & $<0.002$ \\
\hline Total score (stanine) & 78 & $2.7 \pm 0.16$ & $<0.001$ & 71 & $0.3 \pm 0.09$ & $<0.002$ & 77 & $0.6 \pm 0.15$ & $<0.001$ & 77 & $1.0 \pm 0.19$ & $<0.001$ \\
\hline Body image (derived) & 84 & $57.63 \pm 3.15$ & & 79 & $10.42 \pm 3.53$ & $<0.006$ & 84 & $14.33 \pm 3.41$ & $<0.001$ & 83 & $11.58 \pm 3.54$ & $<0.003$ \\
\hline \multicolumn{13}{|l|}{ VASp } \\
\hline Alertness & 90 & $74.3 \pm 1.33$ & & 90 & $-0.5 \pm 1.28$ & & 90 & $0.5 \pm 1.33$ & & 88 & $-0.1 \pm 1.32$ & $<0.453$ \\
\hline
\end{tabular}

Values are given as mean \pm SEM. ${ }^{a}$ Deviation from reference values.

the reference population. However, at $\mathrm{BL}, 88 \%$ of children were within the normal range for internalizing behaviour problems. Following 12 and 24 months in the study this percentage had increased to $93 \%$. As early as 3 months after the start of GH treatment, significantly lower levels of internalizing problems were noted relative to $\mathrm{BL}$ and these were maintained at 12 and 24 months ( $p<0.001$ at all time points). The mean decrease in internalizing behavioural problems was similar irrespective of whether the dose received was individualized or fixed. However, the variation around the mean level was significantly narrower (48\% reduction) for the group on the individualized GH dose than the group on the fixed dose ( $<<$ 0.018 Levene test; fig. 1 ).

In contrast to all other dimensions of the CBCL, externalizing problems increased during $\mathrm{GH}$ treatment. At $\mathrm{BL}$, levels for externalizing behaviour were significantly below the reference population $(\mathrm{p}<0.001)$, and compared to $\mathrm{BL}$, the levels for externalizing behaviour increased significantly at all time points $(\mathrm{p}<0.060, \mathrm{p}<0.007$, $\mathrm{p}<$ 0.040 ) and reached the mean (SDS $=0$ ) of the reference population after 24 months on GH treatment. 
Fig. 1. Parental evaluation of internalizing behaviour problems, a dimension of CBCL of children receiving $\mathrm{GH}$, either randomized to individualized $\mathrm{GH}$ dose (- - ) or a fixed standard GH dose (- - -). a Mean levels and 95\% confidence interval of the total sample are given at BL and 3,12, and 24 months in study. Significant difference vs. BL values at 3,12 , and 24 months are shown: ${ }^{* *} \mathrm{p}<0.001$. b Mean levels and $95 \%$ confidence interval at 2 years are given. At 2 years, there was a reduction of very high values (i.e. improvement for the child), and a significantly narrower variation of internalizing behaviour problems in children on an individualized GH compared to a fixed standard $\mathrm{GH}$ dose ( $p<0.018$ Levene test).

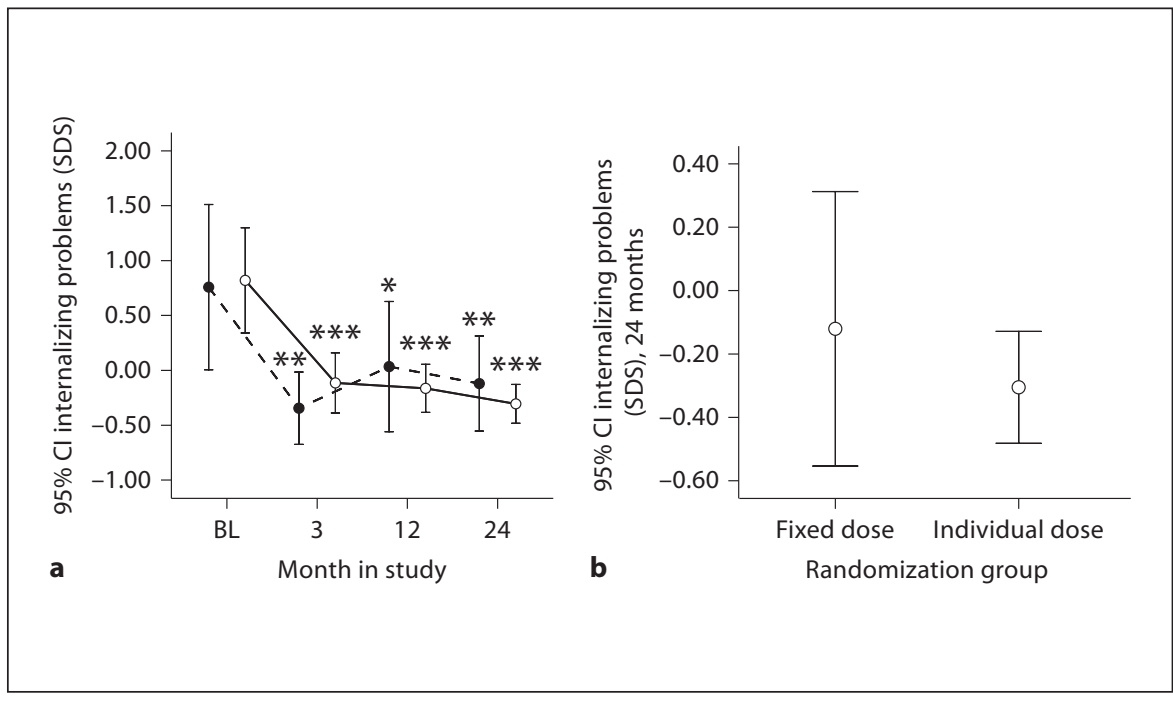

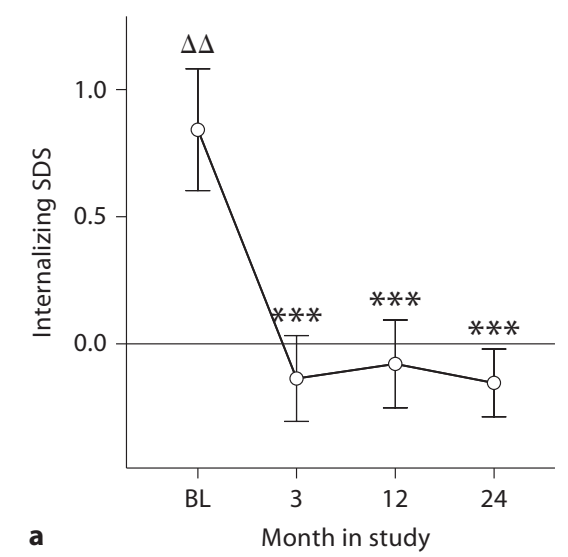

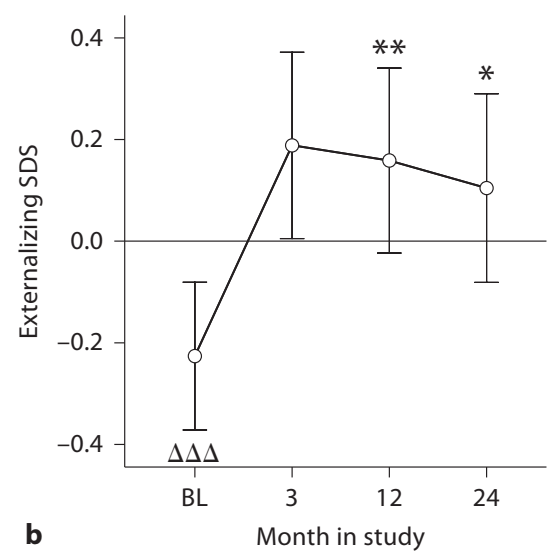

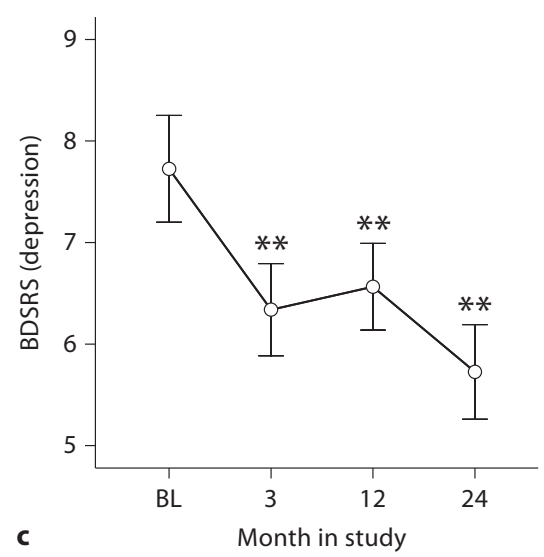

Fig. 2. Parental evaluation of internalizing behaviour problem (a), externalizing behaviour problem dimensions of CBCL (b), and BDSRS (c) at BL, 3, 12, and 24 months on GH treatment. Mean values and SEM are given; significant differences between $\mathrm{BL}$ and 3,12 , and 24 values are given: ${ }^{*} \mathrm{p}<0.05,{ }^{* *} \mathrm{p}<0.01,{ }^{* * *} \mathrm{p}<0.001$.
At BL, the values were significantly elevated $\left({ }^{\Delta \Delta} \mathrm{p}<0.01\right)$ for internalizing problems, and decreased $\left({ }^{\Delta \Delta \Delta} \mathrm{p}<0.001\right)$ for externalizing problems. Depression scores for the entire group were not significantly different at BL compared to the reference values.

\section{Birleson Depression Self-Rating Scale - BDSRS}

(table 2; fig. 2)

At BL, $14 \%$ of the study population were above the cutoff for clinical intervention ( $>15$ points). After 3 months on $\mathrm{GH}$ treatment, a significant reduction in depression scores was observed $(\mathrm{p}<0.003)$, which was maintained at 12 months $(\mathrm{p}<0.010)$ and 24 months $(\mathrm{p}<0.003)$. By the 24 th month, only $5 \%$ of the population scored above the clinical cut-off level to be compared to $2 \%$ in the reference population. Overall, depression levels reduced during the entire study period (table 2; 3 months, $\mathrm{p}<$ $0.003 ; 12$ months, $\mathrm{p}<0.010 ; 24$ months, $\mathrm{p}<0.003)$ and especially so for the ISS subgroup ( 3 months, $\mathrm{p}<0.010$; 12 months, $\mathrm{p}<0.025 ; 24$ months, $\mathrm{p}<0.014)$ but not for 
Table 3. Multivariate regression analyses in the total study group on BL observations and changes from BL up to 3, 12 , and 24 months on $\mathrm{GH}$ treatment ${ }^{\mathrm{a}}$

a Behaviour variables

\begin{tabular}{|c|c|c|c|c|c|c|c|c|c|c|}
\hline & $\Delta$ & $\begin{array}{l}\text { Adj } \\
\mathrm{R}^{2}\end{array}$ & $\begin{array}{l}\mathrm{R}^{2}, \\
\mathrm{BL}\end{array}$ & $\mathrm{BL}$ & $\begin{array}{l}\text { Age, } \\
\text { BL }\end{array}$ & Gender & $\begin{array}{l}\text { Height } \\
\text { gain }\end{array}$ & $\mathrm{GH}_{\max }$ & $\operatorname{diffMPH}_{\mathrm{SDS}}$ & $\begin{array}{l}\text { Birth } \\
\text { length }_{\text {SDS }}\end{array}$ \\
\hline \multicolumn{11}{|l|}{$C B C L$} \\
\hline \multirow{2}{*}{ Internalizing problems SDS } & 12 months & 72 & 67 & $-0.81^{1}$ & & & & \multirow{3}{*}{$-0.01^{1}$} & $0.74^{2}$ & \\
\hline & 24 months & 80 & 79 & $-0.77^{1}$ & & & & & & \\
\hline Withdrawn SDS & $\mathrm{BL}$ & 6 & & & $0.11^{1}$ & & & & & \\
\hline \multirow[t]{3}{*}{ Somatic complaints SDS } & $\mathrm{BL}$ & 8 & 4 & & & $-0.47^{2}$ & \multirow{3}{*}{$-0.43^{2}$} & & & \multirow[t]{3}{*}{$0.30^{1}$} \\
\hline & 3 months & 51 & 49 & $-0.81^{1}$ & & & & & & \\
\hline & 12 months & 24 & 17 & $-0.61^{1}$ & $-0.16^{2}$ & $-0.63^{3}$ & & & & \\
\hline Externalizing problems SDS & $\mathrm{BL}$ & 21 & 16 & & $0.17^{1}$ & & & & & $0.28^{2}$ \\
\hline Rule-breaking SDS & 3 months & 38 & 30 & $-0.48^{1}$ & & $0.61^{2}$ & $0.88^{2}$ & & $-0.48^{3}$ & \\
\hline \multirow[t]{3}{*}{ Depression } & 3 months & 48 & 32 & $-0.52^{1}$ & \multirow{3}{*}{$\begin{array}{l}-0.65^{2} \\
-0.53^{2}\end{array}$} & $1.46^{3}$ & & & & \\
\hline & 12 months & 48 & 43 & $-0.66^{1}$ & & & & & & \\
\hline & 24 months & 64 & 62 & $-1.15^{1}$ & & $2.35^{2}$ & & & & \\
\hline
\end{tabular}

the GHD subgroup. This was true for both boys and girls. The reduction for boys was significant at 3,12 , and 24 months $(-1.7 \pm 3.90,-1.3 \pm 4.54$ and $-2.3 \pm 5.58, \mathrm{p}<$ $0.007, p<0.040$ and $p<0.004$, respectively), whereas the reductions for girls were not significant.

Hyperactive-Inattentive Behaviours - Connors' APTQ

At BL, boys and girls differed significantly on measures: inattention for boys $1.7 \pm 2.22$ and for girls $0.9 \pm$ 1.33 ( $\mathrm{p}<0.025$ ); hyperactivity boys $2.8 \pm 3.16$ and girls $1.6 \pm 2.56(\mathrm{p}<0.044)$; total score boys $4.6 \pm 4.82$ and girls $2.5 \pm 3.68(\mathrm{p}<0.014)$. A decrease in hyperactivity score over time was observed for boys in contrast to an increase for girls; at 3 months, boys had decreased -0.4 \pm 2.68 and girls increased $0.6 \pm 1.8$ (between gender $\mathrm{p}<0.015)$. Similar results were found after 24 months: inattention score decreased in boys $-0.7 \pm 2.56$ and increased in girls $0.9 \pm 2.52(\mathrm{p}<0.009)$; total scores for boys $-1.5 \pm 5.62$ and for girls $2.0 \pm 5.83$ (p $<0.011$ ). Problems significantly decreased in boys over the 2-year study period in attention $(\mathrm{p}<0.034)$ and total APTQ scores also significantly decreased $(\mathrm{p}<0.045)$. At BL, $6 \%$ of children scored above the clinical cut-off ( $>15$ points) for hyperactive-inattentive behaviours, whereas after 24 months on GH the percentage had decreased to $2 \%$.

\section{Explanatory Variables for Behavioural Variables} (table 3a)

In multiple stepwise regression analyses, the BL observation for each specific QoL variable entered significantly $(\mathrm{p}<0.001)$ and negatively as the strongest predictor of variation in changes of the behavioural variables, i.e. children with the worst scores (high scores) at BL improved most during treatment (table 3a). Age, gender, gain in height or $\mathrm{GH}_{\max }$ entered as second predictors. Over the study period it was the older children and boys who benefited most in terms of improvements in problem behaviours and depression.

The magnitude of the changes in CBCL scores during $\mathrm{GH}$ treatment was explained by age, gender, height gain,

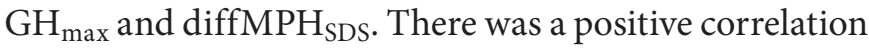
at 12 months between height gain and change of rulebreaking behaviour $(\mathrm{p}<0.007)$, which indicated that the greater the height gain, the more the decrease in rulebreaking behaviour. Regarding internalizing behaviour, 
Table 3. Multivariate regression analyses in the total study group on BL observations and changes from BL up to 3, 12 , and 24 months on GH treatment ${ }^{\mathrm{a}}$

b Psychosocial variables

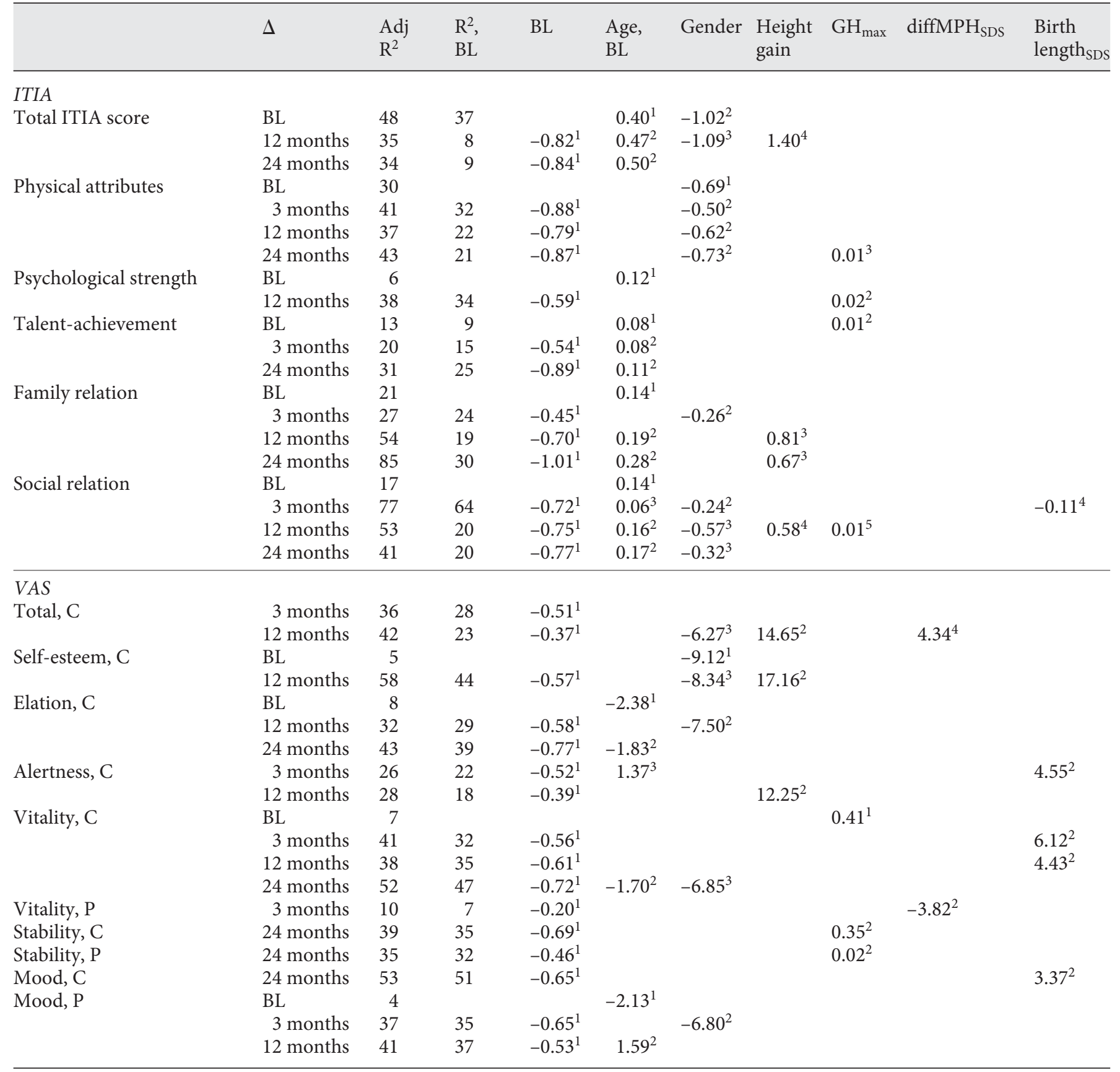

${ }^{a}$ Unadjusted regression coefficients and indices that indicate order of entrance. $\mathrm{R}^{2}$ indicates total $\mathrm{R}^{2}$ adjusted, and $\mathrm{R}^{2}$, $\mathrm{BL}$ indicates explanatory value after inclusion of BL observation. Height gain for BL observation is height $\mathrm{SDS}_{\mathrm{S}}$ at BL. Only results from analyses where predictors, excluding BL observations, were significant are given. ${ }^{1-5}$ Order of entry into the multivariate regression. 


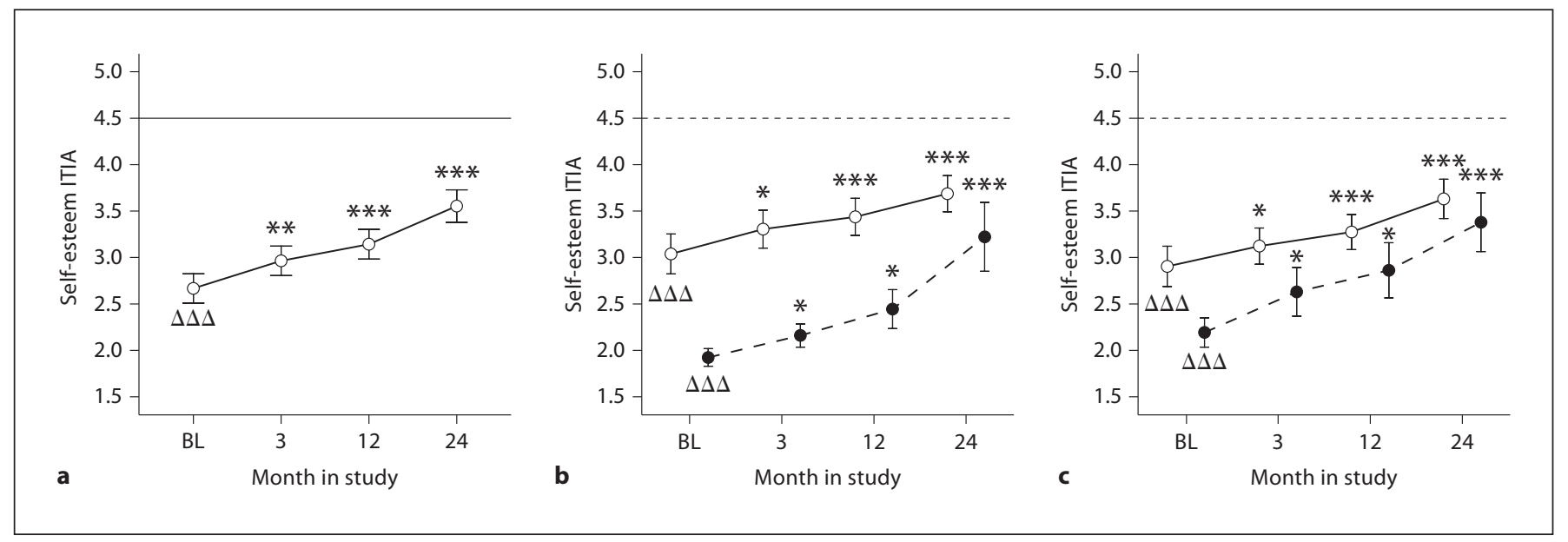

Fig. 3. Self-estimation of self-esteem, as evaluated by ITIA for the total self-esteem score are given as mean values \pm SEM at BL, and 3, 12, and 24 months on GH treatment: (a) the total group, (b) boys (- - -) and girls $(-)$, and (c) GHD (- - ) and ISS (- - . Significant change vs. BL values are given: ${ }^{*} \mathrm{p}<0.05,{ }^{* *} \mathrm{p}<0.01$, ${ }^{* * *} \mathrm{p}<0.001$. At baseline the self-esteem values were significantly below the average for the reference data $\left({ }^{\Delta \Delta} \mathrm{p}<0.001\right)$

more improvements were noted in those children who had higher $\mathrm{GH}_{\max }$ and in children in whom the current height ${ }_{S D S}$ differs most to $\mathrm{MPH}_{\mathrm{SDS}}$.

The changes in depression score (BDSRS) were explained by BL levels, age and gender, with older children and boys improving most; $48 \%$ of the variance was explained at 3 and 12 months and $64 \%$ at 24 months. $\mathrm{GH}_{\max }$ was the second explanatory variable to explain the variation in over-activity and total APTQ scores, with a greater improvement in attention associated with a higher $\mathrm{GH}$ secretion. In addition, children who had least difference in their height ${ }_{S D S}$ versus their target height $\left(\mathrm{MPH}_{\mathrm{SDS}}\right) \mathrm{im}$ proved most.

\section{Assessment of Psychosocial Variables}

Self-Esteem Profile ITIA (table 2; fig. 3)

At BL, the mean total self-esteem was evaluated as 2.7 \pm 1.39 , i.e. significantly lower than the mean (score 5 ) of the reference population $(\mathrm{p}<0.001)$. Girls scored lower, $1.9 \pm 0.48$, than boys, $3.0 \pm 1.55(\mathrm{p}<0.001)$, and older children scored higher than younger children $(\rho=0.57$; $\mathrm{p}<0.001$ ). Following GH treatment, there was an improvement in total self-esteem at 3 months $(\mathrm{p}<0.002)$ with further improvement at 12 and 24 months $(\mathrm{p}<0.001)$ (table 2). Boys were found to improve more than girls.

Well-Being Profile VASc \& VASp (table 2; fig. 4)

No significant changes were detected in the child's own estimation of well-being scores (VASc). The parental well-being profile showed an improvement after 3, 12 and 24 months of follow-up for the dimensions of stability $(\mathrm{p}<0.025, \mathrm{p}<0.029, \mathrm{p}<0.008$, respectively) and mood ( $\mathrm{p}<0.039, \mathrm{p}<0.021, \mathrm{p}<0.036$, respectively). The improvements were seen at the 3-month visit and maintained thereafter for children with ISS, whereas values for the GH-deficient children levelled off (table 2).

\section{Explanatory Variables for Psychosocial Variables (table 3b)}

The BL level of each psychosocial dimension was the strongest explanatory variable - always negatively correlated to the change occurring during $\mathrm{GH}$ treatment. Older children scored higher than younger children at $\mathrm{BL}$ and improved more on the self-esteem ITIA dimensions, whereas older children scored lower than younger children on the well-being VAS scales. Gain in height ${ }_{\text {sDs }}$ was also positively correlated to changes, indicating greater improvements of self-esteem with more gain in height. After both 12 and 24 months, various well-being and self-esteem variables were positively associated with the $\mathrm{GH}_{\text {max }}$, indicating that the ISS children improved most in psychosocial variables including physical attributes, psychological strength, social relationships and the wellbeing dimension of stability. 


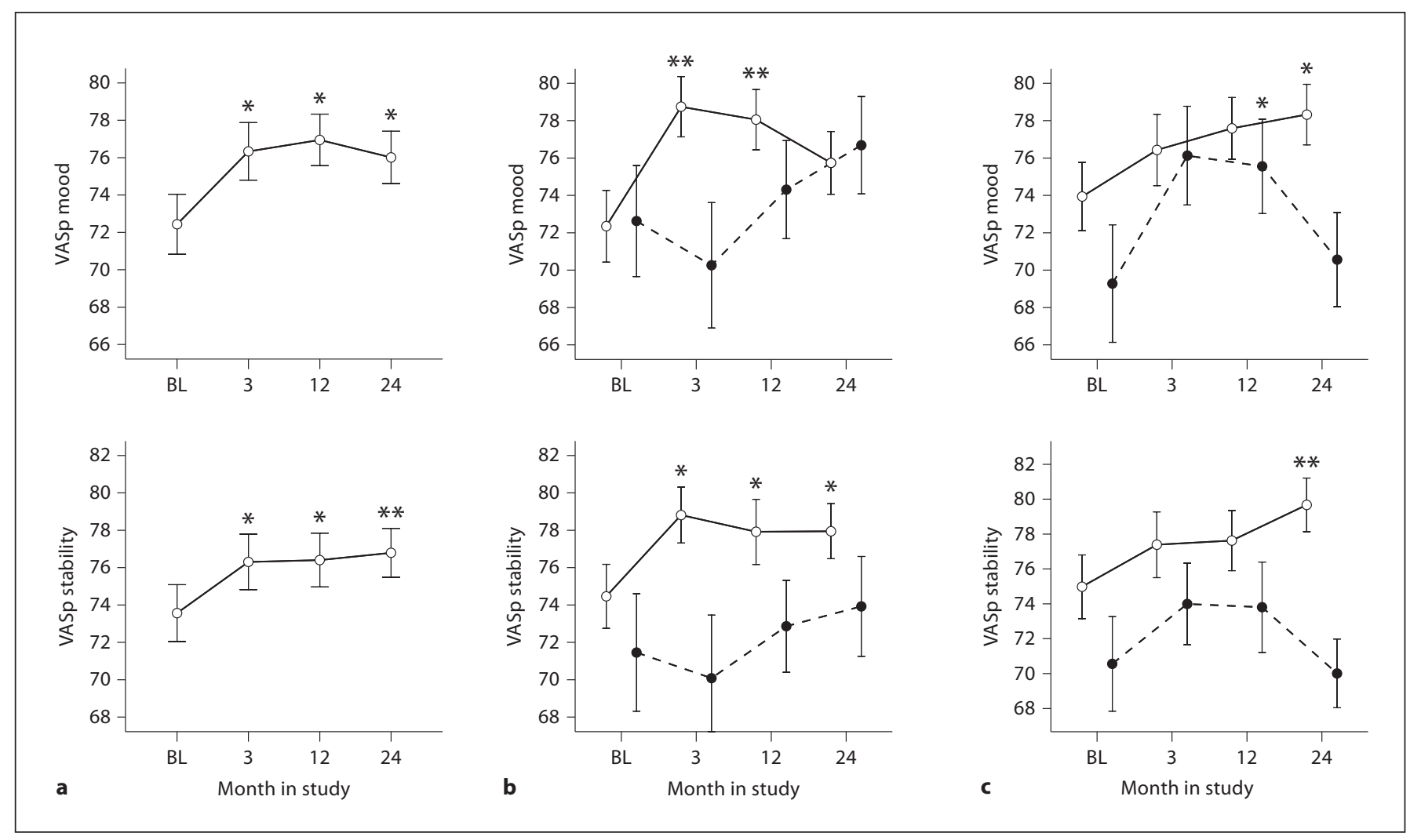

Fig. 4. Evaluation by the parent of well-being as estimated by VAS at BL and 3, 12, and 24 months on GH treatment: (a) total study group, (b) boys (_- ) and girls $(---)$, and (c) ISS (- - ) and GHD (- - $)$. Statistically significant changes from BL are indicated: ${ }^{*} \mathrm{p}<0.05 ;{ }^{* *} \mathrm{p}<0.01$.

\section{Discussion}

Our primary objective was to carry out a longitudinal evaluation of specific behavioural and psychosocial characteristics in a study of referred short-stature prepubertal GHD and ISS children, randomized to either an individualized GH dose or a fixed standard dose. In both groups, a reduction in behavioural problems as well as depression scores were observed within the first 3 months of treatment, and this gain was maintained throughout the study period in both boys and girls. The variation in response of markers of QoL to GH was explained by BL evaluation, the age, gender, $\mathrm{GH}_{\max }$, height gain and difference between current and target, i.e. mid-parental height (SDS). Thus, younger children, boys, and those with a greater height gain showed the greatest reduction in internalizing problems, depression and hyperactivity and the best improvement of psychosocial variables. Psychosocial outcomes, such as self-esteem and well-being, signifi- cantly improved. In terms of self-esteem, it was the older boys who benefited most.

\section{Behaviour and Depression}

We transformed CBCL variables into SDS based on a Swedish reference population in order to adjust for age and gender in our study group. In comparison with the reference population, we found significantly higher BL values for internalizing problems, total problems, social relations and rule-breaking behaviour. In the present study, there were substantial improvements in many problem areas following $\mathrm{GH}$ treatment. There were statistically significant improvements in behaviour for the group as a whole in terms of internalizing problems, irrespective of whether diagnosed as isolated GHD or ISS. This confirms previous reports in short prepubertal children. Stabler et al. $[33,34]$ reported a significantly higher total score for behavioural problems in children with either isolated GHD or ISS. Their finding was based on 
higher internalizing subscale scores (withdrawn, somatic complications, and anxious/depressed) and greater problems with attention, social problems and thought problems. These problems all decreased after 3 years on GH treatment. In children born SGA, treated with long-term $\mathrm{GH}$ to $\mathrm{FH}$, the Hokken-Koelega group [4] found that prepubertal children scored higher at BL than the Dutch normal population on total externalizing and behavioural problems. Furthermore, problem scores decreased during $\mathrm{GH}$ treatment such that they were comparable to Dutch peers at the end of the study. In a randomized, controlled GH treatment study in peripubertal children with ISS to FH, Ross et al. [35] found a deviation from BL scores on the CBCL for total, internalizing and externalizing behavioural problems, all of which improved in the later stages of puberty. Similar results were also found in another Dutch study [10] of prepubertal children with ISS, where higher levels of internalizing problems (withdrawn and anxious/depressed) as well as higher scores for social problems and attention problems were reported at $\mathrm{BL}(0.15-0.37$ SDS difference to the mean (SDS =0)). Taken together with our findings that psychosocial and behavioural improvements were apparent already after 3 months of treatment and were maintained after 12 and 24 months, it would indicate evidence firstly that short prepubertal children have more problems than are observed in reference populations and secondly that these variables normalize early during a 2-year period of $\mathrm{GH}$ treatment.

Our finding that the levels of depression in short children reduced after 3 months on GH treatment is in accordance with a recent study in peripubertal children with isolated GHD [36]. However, we found a gender difference for depression scores. Depression decreased more during treatment in boys than in girls. Knowing that there is a higher incidence of suicide later in life in short men than in men of normal height (a $5-\mathrm{cm}$ increase in height was associated with a $90 \%$ decrease in suicide risk) [16] highlights the importance of childhood exposure to depression in short children. In adults, depression is a well-known sign of GHD [37]. In fact, scores on most behaviour variables were higher at BL in our cohort than in the reference population, and the scores normalized within 2 years on GH treatment; the best results were seen in patients with the highest GH secretion. Social problems and problems of acceptance by peers often become clinically apparent late, i.e. when the child had reached adolescence or even later in life $[15,16]$, whereas for $\mathrm{GH}$ treatment to be most effective it is important to start treatment early in the child's life. This means that
GH treatment can be considered to have a preventive rather than curative impact on QoL problems. If we wait for major problems to occur, it might be too late to effectively overcome problems which could be ameliorated by earlier height gain.

Previous research has indicated a connection between growth and anxiety [38], especially in girls [39]. It has been proposed that anxiety may blunt hormone responses at the hypothalamic level thus resulting in low $\mathrm{GH}$ secretion [39]. It was also shown that this occurs less in boys than in girls, in whom emotional disorders have greater persistence [40]. In our study, we can partially confirm the association between short stature and anxiety. Following GH treatment, there was a significant reduction in anxiety after 3 months of treatment which was greater in girls than in boys, and mainly in the ISS group compared to the GH-deficient group.

\section{Psychosocial Estimates, Self-Esteem and Well-Being}

Gain in height was positively correlated with improvements in psychosocial variables. Further, endogenous $\mathrm{GH}_{\max }$ correlated positively with changes of the variables, indicating that ISS improved more than GH-deficient children. The differences between the GH-deficient and ISS groups are interesting and, given the continuous nature of GH secretion and that the categorization here is arbitrary, it is surprising that a difference was found. Children with ISS showed greater increases in self-esteem and well-being than were found in the $\mathrm{GH}$-deficient group. However, in general, it might be concluded that in some children the gain in height alone may not be enough to influence social acceptance and provide psychological benefit. It has been pointed out that children with low $\mathrm{GH}$ secretion tend to be inhibited, socially withdrawn and lack maturity $[7,41]$. Children with low energy levels are unlikely to have a large social network. Height increase, if this negates a social exclusion, may therefore not provide an immediate advantage for the GH-deficient child. This may explain why there is apparently more gain in self-esteem in the ISS group. The differences between GHD and ISS may help to explain why there are contradictory findings concerning QoL benefits $[4,42]$. It is interesting to note that the documented improvement in psychosocial and behaviour outcomes in the SGA children of the Netherland study [4] could not be documented in the short-term Belgian SGA study [18]. Knowing the broad range of $\mathrm{GH}$ secretion in children born SGA, with half of them with low GH secretion $[43,44]$, leads us to speculate that there might be different subpopulations of SGA children regarding GH secretion capacity in the two 
studies, namely the Belgian study population being more $\mathrm{GH}$-deficient and behaving as the GHD children in the present study.

Due to the study design, the study group is representative of short children referred to a growth clinic only. Thus, it might represent those with less coping and more problems due to their short stature. Interestingly, we find an overrepresentation of the lower, and an underrepresentation of the middle education category, mirroring referral strategies. The overrepresentation of parents with basic level education is expected in a population of shortstature children [45] and corresponds to clinical expectations.

Since the primary goal was height gain to target height $\left(\mathrm{MPH}_{\mathrm{SDS}}\right)$, there was a requirement of at least $1 \mathrm{SD}$ in diffMPH$_{\text {SDS }}$ at study start. Thus, children with FSS were excluded. By definition today, children with FSS should not be included in an ISS population, having a genetic background to their short stature. Moreover, it has been shown earlier that children with FSS barely respond to GH treatment [3] and therefore should not be included in treatment trials not focusing on problems in this specific subgroup of short children.

The study population of children with short stature was chosen with a broad range of GH secretion. Thus, not only children with classical severe GHD were included, but also all children with a $\mathrm{GH}_{\max }<10 \mu \mathrm{g} / \mathrm{l}$, defined as GHD, as well as children with a $\mathrm{GH}_{\max }$ above this cut-off level, i.e. ISS when estimated from $\mathrm{GH}_{\max }$ of provocation tests. However, with a goal to be as precise as possible regarding the diagnoses, we added information of the spontaneous 24-hour profile, and reclassified the study population into the subgroups called 'GHD' and 'ISS' that were further analyzed in the present study. Unfortunately, during the 3 years of inclusion in the study, only a few children with severe isolated GHD were found.

The lack of an untreated control arm in the study makes it difficult to draw concrete conclusions. The fact that $75 \%$ of the study population should have received $\mathrm{GH}$ treatment on clinical grounds, having low $\mathrm{GH}_{\max }$ on provocation tests, made it unethical to have a randomized untreated control group. Absence of a control group is a concern for all GH studies in short children within approval indications for $\mathrm{GH}$ treatment.

Another concern of the present study is that the changes observed over time could be interpreted as regression towards the mean (RTM). However, the longitudinal nature of the study design would suggest greater variation between time points if RTM was an explanatory factor.
The initial 3-month change is substantially different from the changes occurring in the subsequent periods, which would not be expected if RTM were an explanatory factor [42]. Secondly, the subjects were not chosen on the basis of extreme scores on the measured variables which would be the most likely reason to expect RTM to occur.

Another potential criticism of the results is that improvements could be related to the fact that the children were under medical follow-up, a problem we share with all studies in this field. However, children included in the study had already undergone a full pretreatment year of diagnostic work-up, and therefore this effect would be weakened by the time of study start. We might expect to see a decrease in QoL scores at subsequent follow-ups, but this was not observed. Positive expectations from receiving $\mathrm{GH}$ treatment cannot be avoided as this is elective therapy.

\section{Conclusion}

Improvements in behaviour and self-esteem can only be beneficial to the growing child, and our results demonstrate that these benefits are in parallel with gain in height. The greatest QoL improvements in the shortstature group as a whole were found in the first 3 months and thereafter maintained, emphasizing the importance of the initial treatment period not only for growth and metabolic changes but also behaviour and psychosocial outcome following $\mathrm{GH}$ treatment. Improvements in behaviour and self-esteem, however, varied between subgroups. The GHD group appeared to benefit less than the ISS group from height gain, and it should be recognised that height gain alone may not be sufficient to improve QoL. We would therefore recommend that in addition to $\mathrm{GH}$ treatment, psychological counselling should be available to maximize the benefit of the GH treatment.

\section{Acknowledgements}

The authors thank the participating children and families, the national study team led by Carola Pfeiffer-Mosesson, regional study teams, colleagues at university paediatric endocrinology centres and colleagues at county hospitals responsible for caring for the children close to home.

The authors are also thankful for the skilled investigations by the psychologist at each site, Ann-Marie Friesendahl and Jeanette Hörnqvist, Umeå; Marianne Bonnert, Susanna Grund and Anna Elmund, Uppsala; Ann-Margret Nordenberg, Halmstad; Åsa Löf- 
gren and Rosalie Säregård, Gothenburg. Harriet Crofts for language editing.

This investigator-initiated study TRN 98-0198-003 was funded by Pharmacia/Pfizer. Financial support was also obtained from Swedish Research Council No. 7509, University Hospital (ALF) and West Sweden Region (VGR) grants.

\section{Disclosure Statement}

Research grants were received by J.E.C., J.D. and K.A.-W. Consulting fees were obtained by J.E.C., B.K., B.J., T.T. and J.D. Consultant in Pfizer ISS Advisory Board: J.E.C. and J.D. Stock options were held by J.D. and A.S.A. B.H. had nothing to declare.

\section{References}

1 Cohen P, Rogol AD, Deal CL, Saenger P, Reiter EO, Ross JL, Chernausek SD, Savage MO, Wit JM: Consensus statement on the diagnosis and treatment of children with idiopathic short stature: a summary of the Growth Hormone Research Society, the Lawson Wilkins Pediatric Endocrine Society, and the European Society for Paediatric Endocrinology Workshop. J Clin Endocrinol Metabol 2008; 93:4210-4217.

- 2 Kriström B, Aronson AS, Dahlgren J, Gustafsson J, Halldin M, Ivarsson SA, Nilsson NO, Svensson J, Tuvemo T, Albertsson-Wikland $\mathrm{K}$ : Growth hormone (GH) dosing during catch-up growth guided by individual responsiveness decreases growth response variability in prepubertal children with GH deficiency or idiopathic short stature. J Clin Endocrinol Metabol 2009;94:483-490.

- 3 Albertsson-Wikland K, Aronson AS, Gustafsson J, Hagenäs L, Ivarsson SA, Jonsson B, Kriström B, Marcus C, Nilsson KO, Ritzen EM, Tuvemo T, Westphall O, Aman J: Dosedependent effect of growth hormone on final height in children with short stature without growth hormone deficiency. J Clin Endocrinol Metabol 2008;93:4342-4350.

-4 Van Pareren YK, Duivenvoorden HJ, Slijper FS, Koot HM, Hokken-Koelega AC: Intelligence and psychosocial functioning during long-term growth hormone therapy in children born small for gestational age. J Clin Endocrinol Metabol 2004;89:5295-5302.

5 Chaplin J, Kriström B, Dahlgren J, Albertsson-Wikland K: Psychological importance to the child of growth hormone replacement. The somatotrophic axis in brain function. Sci Technol Life Sci 2006;19:249-266.

-6 Theunissen NC, Kamp GA, Koopman HM, Zwinderman KA, Vogels T, Wit JM: Quality of life and self-esteem in children treated for idiopathic short stature. J Pediatr 2002;140: 507-515.

7 Erling A, Wiklund I, Albertsson-Wikland K: Psychological functioning in boys of short stature: effects of different levels of growth hormone secretion. Acta Paediatr 2002;91: 966-971.

8 Erling A, Wiklund I, Albertsson-Wikland K: Prepubertal children with short stature have a different perception of their well-being and stature than their parents. Qual Life Res 1994;3:425-429.
9 Voss LD, Bailey BJ, Mulligan J, Wilkin TJ, Betts PR: Short stature and school performance - the Wessex Growth Study. Acta Paediatr Scand 1991;377:29-32.

10 Visser-van Balen H, Geenen R, Kamp GA, Huisman J, Wit JM, Sinnema G: Motives for choosing growth-enhancing hormone treatment in adolescents with idiopathic short stature: a questionnaire and structured interview study. BMC Pediatr 2005;5:1-11.

11 Downie AB, Mulligan J, Stratford RJ, Betts PR, Voss LD: Are short normal children at a disadvantage? The Wessex Growth Study. BMJ 1997;314:97-100.

12 Busschbach JJ, Rikken B, Grobbee DE, De Charro FT, Wit JM: Quality of life in short adults. Horm Res 1998;49:32-38.

13 Steinhausen HC, Dorr HG, Kannenberg R, Malin Z: The behavior profile of children and adolescents with short stature. J Dev Behav Pediatr 2000;21:423-428.

14 Voss LD: Short stature: does it matter? A review of the evidence. J Med Screen 1995;2: 130-132.

15 Christensen TL, Djurhuus CB, Clayton P, Christiansen JS: An evaluation of the relationship between adult height and healthrelated quality of life in the general UK population. Clin Endocrinol 2007;67:407-412.

16 Magnusson PK, Gunnell D, Tynelius P, Davey Smith G, Rasmussen F: Strong inverse association between height and suicide in a large cohort of Swedish men: evidence of early life origins of suicidal behavior? Am J Psychiatry 2005;162:1373-1375.

17 Erling A: Why do some children of short stature develop psychologically well while others have problems? Eur J Endocrinol/Eur Fed Endocr Soc 2004;151(suppl 1):S35-S39.

18 Lagrou K, Froidecoeur C, Thomas M, Massa
L G, Beckers D, Craen M, de Beaufort C, Rooman R, Francois I, Heinrichs C, Lebrethon MC, Thiry-Counson G, Maes M, De Schepper J: Concerns, expectations and perception regarding stature, physical appearance and psychosocial functioning before and during high-dose growth hormone treatment of short pre-pubertal children born small for gestational age. Horm Res 2008;69:334-342.
9 Brutt AL, Sandberg DE, Chaplin J, Wollmann H, Noeker M, Koltowska-Haggstrom M, Bullinger M: Assessment of health-related quality of life and patient satisfaction in children and adolescents with growth hormone deficiency or idiopathic short stature. Part 1: A critical evaluation of available tools. Horm Res 2009;72:65-73.

20 Bullinger M, Koltowska-Haggstrom M, Sandberg D, Chaplin J, Wollmann H, Noeker M, Brutt AL: Health-related quality of life of children and adolescents with growth hormone deficiency or idiopathic short stature. Part 2: Available results and future directions. Horm Res 2009;72:74-81.

21 Howe LD, Tilling K, Galobardes B, Smith GD, Gunnell D, Lawlor DA: Socioeconomic differences in childhood growth trajectories: at what age do height inequalities emerge? J Epidemiol Community Health 2010 (in press).

22 Albertsson-Wikland K, Luo ZC, Niklasson A, Karlberg J: Swedish population-based longitudinal reference values from birth to 18 years of age for height, weight and head circumference. Acta Paediatr 2002;91:739754.

23 Jansson C, Boguszewski C, Rosberg S, Carlsson L, Albertsson-Wikland K: Growth hormone $(\mathrm{GH})$ assays: influence of standard preparations, GH isoforms, assay characteristics, and GH-binding protein. Clin Chem 1997;43:950-956.

24 Achenbach TM: Manual for the ASEBA School-Age Forms and Profiles. Burlington, University of Vermont, Research Centre for Children, Youth \& Families, 2001.

25 Achenbach TM, Dumenci L, Rescorla LA: Are American children's problems still getting worse? A 23-year comparison. J Abnorm Child Psychol 2003;31:1-11.

26 Achenbach TM, Howell CT, McConaughy SH, Stanger C: Six-year predictors of problems in a national sample. IV. Young adult signs of disturbance. J Am Acad Child Adolesc Psychiatry 1998;37:718-727.

27 Larsson B, Frisk M: Social competence and emotional/behaviour problems in 6- to 16 -year-old Swedish school children. Eur Child Adolesc Psychiatry 1999;8:24-33.

28 Birleson P: The validity of depressive disorder in childhood and the development of a self-rating scale: a research report. J Child Psychol Psychiatry 1981;22:73-88. 
29 Birleson P: Depression in childhood. Aust Paediatr J 1986;22:7-10.

30 Sprague RL, Cohen MN, Werry JS: Normative data on the Conner's Teacher Rating Scale and Abbreviated Scale. Champaign, Institute of Child Behavior and Development, 1974.

31 Ouvinen-Birgestam P: I Think I Am... (Jag Tycker Jag Är...), ed 1. Stockholm, Psychology Society, 1985.

- 32 Wiklund I, Wiren L, Erling A, Karlberg J, Albertsson-Wikland K: A new self-assessment questionnaire to measure well-being in children, particularly those of short stature. Qual Life Res 1994:3:449-455.

-33 Stabler B, Clopper RR, Siegel PT, Stoppani C, Compton PG, Underwood LE: Academic achievement and psychological adjustment in short children. The National Cooperative Growth Study. J Dev Behav Pediatr 1994;15: 1-6.

- 34 Stabler B, Siegel PT, Clopper RR, Stoppani CE, Compton PG, Underwood LE: Behavior change after growth hormone treatment of children with short stature. J Pediatr 1998; 133:366-373.
- 35 Ross JL, Sandberg DE, Rose SR, Leschek EW, Baron J, Chipman JJ, Cassorla FG, Quigley CA, Crowe BJ, Roberts K, Cutler GB Jr: Psychological adaptation in children with idiopathic short stature treated with growth hormone or placebo. J Clin Endocrinol Metabol 2004;89:4873-4878.

36 Abe S, Okumura A, Mukae T, Nakazawa T, Niijima S, Yamashiro Y, Shimizu T: Depressive tendency in children with growth hormone deficiency. J Paediatr Child Health 2009;45:636-640.

37 Koltowska-Haggstrom M, Mattsson AF, Monson JP, Kind P, Badia X, Casanueva FF, Busschbach J, Koppeschaar HP, Johannsson G: Does long-term GH replacement therapy in hypopituitary adults with GH deficiency normalise quality of life? Eur J Endocrinol/ Eur Fed Endocr Soc 2006;155:109-119.

38 Uhde TW: Anxiety and growth disturbance: is there a connection? A review of biological studies in social phobia. J Clin Psychiatry 1994;55(suppl):17-27.

39 Pine DS, Cohen P, Brook J: Emotional problems during youth as predictors of stature during early adulthood: results from a prospective epidemiologic study. Pediatrics 1996;97:856-863.

40 McGee R, Feehan M, Williams S, Anderson J: DSM-III disorders from age 11 to age 15 years. J Am Acad Child Adolesc Psychiatry 1992:31:50-59.
41 Rotnem D, Genel M, Hintz RL, Cohen DJ: Personality development in children with growth hormone deficiency. J Am Acad Child Psychiatry 1977;16:412-426.

42 Majnu J, Abbas F: Assessing the regression to the mean for non-normal populations via kernel estimators. North Am J Med Sci 2010; 2:288

43 Albertsson-Wikland K, Niklasson A, Karlberg P: Birth data for patients who later develop growth hormone deficiency: preliminary analysis of a national register. The Executive Scientific Committee of the Kabi International Growth Study and the Swedish Paediatric Study Group for Growth Hormone Treatment. Acta Paediatr Scand 1990; 370:115-121.

44 Boguszewski M, Rosberg S, AlbertssonWikland K: Spontaneous 24-hour growth hormone profiles in prepubertal small for gestational age children. J Clin Endocrinol Metabol 1995;80:2599-2606.

45 Cavelaars AE, Kunst AE, Geurts JJ, Crialesi R, Grotvedt L, Helmert U, Lahelma E, Lundberg O, Mielck A, Rasmussen NK, Regidor E, Spuhler T, Mackenbach JP: Persistent variations in average height between countries and between socio-economic groups: an overview of 10 European countries. Ann Hum Biol 2000;27:407-421. 